\title{
Biosensors functionalized with nanoparticles for rapid detection of Brucella
}

\author{
Azam Ahangari ${ }^{1}$, Pezhman Mahmoodi ${ }^{1}$, and Abdolmajid Mohammadzadeh ${ }^{1}$ \\ ${ }^{1} \mathrm{Bu}$ Ali Sina University
}

May 4, 2021

\begin{abstract}
Brucellosis is an infectious bacterial disease that mainly affects ruminants and humans and its detection is still a significant challenge in particular, in the developing countries. At present, methods used to diagnose brucellosis consist of microbiological, biochemical, immunological, and molecular techniques which may be time-consuming, laborious, expensive, and dependent on special equipment, while they may not be suitable for on-site miniaturized detection. Thus, development of novel methods that can characterize Brucella spp with minimal equipment is invaluable for rapid and easy detection of these pathogenic bacteria especially in basic laboratories or even in the farm fields. The nanotechnology-driven approach can be successfully applied using different nanoparticles for the diagnosis of pathogens. Nanobiosensors are therefore, one of those promising solutions in this case. These sensors are efficient tools with diverse biological applications which can identify pathogenic bacteria with relatively high sensitivity and specificity. In this context, new nanobiosensors, developed based on various nanoparticles, for rapid detection of Brucella spp have been discussed.
\end{abstract}

\section{Introduction}

Brucella are facultative intracellular bacteria that cause infections in animals and humans called brucellosis. So far, ten species have been characterized with four typical species (Brucella melitensis , Brucella abortus , Brucella suis, andBrucella canis ) which are known to cause disease in humans (S. Li et al., 2019; Pal et al., 2017). Although brucellosis is a common zoonotic disease, it is believed that humans are encountered accidentally (Taheri, Amini, Kamali, Asadi, \& Naderlou, 2020). The disease is associated with acute symptoms including fever, lethargy, chill, weight loss, and arthralgia in humans. However, the infection may affect various organs and become chronic with signs such as osteomyelitis, orchitis, and endocarditis, etc (Pereira et al., 2020). But in animals, the infection may cause abortion storm in sensitive herds and therefore, it is very important in livestock and quick diagnosis is necessary to prevent the spread of the infection and subsequent economic losses (Taheri et al., 2020).

Blood culture is considered as the gold standard method to identifyBrucella spp. Hwoever, a sensitivity around $15 \%$ to $70 \%$ has been reported for this method respect to the PCR (Polymerase chain reaction) assay. Meanwhile, several serological tests are used to detect infections caused by Brucella spp, including the Bengal Rose test, 2-mercaptoethanol, Wright, Coombs Wright, and serum agglutination test. Nevertheless, they have low sensitivity and specificity, long response time, false positive result, operational complexity, and difficulties in real-time monitoring (Alves et al., 2010).

On the other side, the molecular techniques that work on the basis of DNA detection like PCR, are not only fast ( $>4$ hour), but also make it possible to molecularly type the isolates without exposure to the infectious Brucella cells (Alves et al., 2010). Yet, the common PCR assay has its own limitations in detection of PCR products and interpretation of the results e.g. lack of convineincy and sensitivity, need for costly equipment, complex sample preparation, and skilled personnel requirement (Sattarahmady, Kayani, \& Heli, 
2015). Consequently, it is extremely important to develop more simple, sensitive, and inexpensive methods for detecting Brucella spp to overcome these limitations (Sattarahmady et al., 2015).

Application of biosensors has been the novel approach for the scientists. \{Sattarahmady, 2015 \#146;Sattarahmady, 2015 \#146\}Using biosensors, the sensitivity and specificity of detection methods have recently been improved for various pathogenic bacteria. Biosensors are analytical biodevices that convert the biological responses into electrical signals. These agents generally consist of a bioreceptor (e.g., antibodies, enzymes, nucleic acids (DNA/RNA/aptamers), microorganisms, etc.) with a physical transducer (optical, electrochemical, or mass-based) to generate a measurable signal (Rubab, Shahbaz, Olaimat, \& Oh, 2018). Many novel signal transduction systems are being developed by using nanoparticles to further improve strategies for detection of pathogens (Narmani et al., 2018).

In this case, several biosensors have been designed based on the engagement of diverse nanoparticles such as magnetic-, silica-, gold-nanoparticles, and quantum dots, and introduced for the characterization of pathogenic bacteria (Ahangari, Salouti, \& Saghatchi, 2016; Narmani et al., 2018). The present review has described the recent developments of various nanobiosensors for the detection of Brucella spp.

\section{Optical biosensors for detection of Brucella spp}

Optical biosensors have extensively been applied for the identification of infectious bacteria because of their sensitivity, rapid response, and adaptability with different assay conditions (Singh, Poshtiban, \& Evoy, 2013). Optical biosensors comprise of a light source, as well as various optical segments to produce a light bar with explicit attributes and a modified sensing head along with a photodetector to beeline this light to a modulating agent (Mehrotra, 2016).

Optical biosensors are classified into subcategories of surface plasmon resonance (SPR), colorimetric, fluorescence, and chemiluminescence sensors (Rubab et al., 2018). Among these, colorimetric sensors make it possible to detect the causative agent in an easier and quicker manner while they are also portable and cost-effective. The attractive colorimetric method allows rapid recognition of pathogens by a color change in the sample in about $15 \mathrm{~min}$. Response signals can be seen with the naked eye without pre-enrichment steps (Rubab et al., 2018).

\subsection{Colorimetric assay for detection of Brucella using gold nanoparticles}

Gold nanoparticles are one of the highly used nanoparticles in the development of biosensors. These nanoparticles possess useful optical properties such as large surface area to volume ratio and stability at high temperatures. The optical properties of gold nanoparticles depend on the size of the particles or the distance between them. So, aggregation of gold nanoparticles will alter their optical properties (Amini, Kamali, Salouti, \& Yaghmaei, 2018; Emameian, Ahangari, Salouti, \& Amirmozafari, 2020; Shahbazi et al., 2018). The proper optical attributes make these nanoparticles excellent optical labels to increase sensitivity of optical biosensors (Eltzov \& Marks, 2016). Based on the physico-chemical properties of gold nanoparticles (AuNP), Sattarahmady et al. developed a colorimetric method to detect genomic DNA of Brucella melitensis in clinical samples. To do this, AuNP-DNA probes were used to investigate a specific DNA sequence of B. melitensis , BMEII0466, which resulted in the color change of the solution from red to purple after hybridization in samples containing $B$. melitensis genomic DNA. One advantage of this method was the visibility of color shift by the naked eye (Sattarahmady et al., 2015).

In another research, Pal et al. reported a new diagnostic test for Brucella, on the basis of hybridization assay using gold nanoparticles, in which the color of the solution was changed following successful detection of a specific DNA sequence of the pathogen by the nanobiosensors. They designed a thiol-modified probe which was specific for an outer membrane protein. Their results showed that the AuNP-oligo probe could be utilized for the rapid detection of Brucella in samples of bovine origin. The detection scheme is given in figure 1 (Pal et al., 2017).

2.2 Sandwich immunoassay based on the silica- and magnetic-nanoparticles for detection of Brucella 
Sandwich immunoassays using nanoparticle-based biosensors have recently received increasing attention as promising approaches for introducing selective and sensitive diagnostic tools (Sun, Zhao, \& Dou, 2016). Silica- and magnetic-nanoparticles show unique features that can be related to their hydrophobic surfaces, ability to change their surfaces with chemical groups, and easy separation by the magnetic force (Taheri et al., 2020).

Magnetic nanoparticles (MNPs) have also been explored for the specific characterization of pathogenic bacteria, as they show remarkable enzyme activity with extremely high stability and they can be mass-produced at low cost. Pathogen-specific receptors like antibodies are therefore conjugated on the surface of the nanoparticles and are utilized to identify bacteria (Le, Tran, \& Kim, 2020).

Shams et al. designed an immunosensor for characterization of Brucella abortus based on the blue-silica nanoparticles (SiNPs) and paramagnetic nanoparticles (PMNPs). The synthesized immunosensor was conjugated with a polyclonal antibody against $B$. abortus and added to the bacterial suspension. Sandwich structure of PMNPs B. abortus -blue-SiNPs was then formed and separated by a magnet. Using a spectrophotometer, the absorbance of the blue color released from the silica structure was measured alongside the visible color shift to assess the presence of the bacterial cells in the samples (Shams, Rahimian Zarif, Salouti, Shapouri, \& Mirzaii, 2019).

In another research, Taheri et al. designed an immunosensor, based on the magnetic- and silica-nanoparticles for detection of $B$. abortus . Consequently, IgG1 was conjugated on the surface of MNPs to form MNPIgG1, and on the other hand, IgG2 and horseradish peroxidase enzyme (HRP) molecules were conjugated on the silica nanoparticles (SNPs) to form HRP-SNP-IgG2. The MNP-IgG1 and HRP-SNP-IgG2 were then added to a sample containing B. abortus to form HRP-SNP-IgG2-B. abortus -IgG1-MNPs complex followed by isolation of the complex using a magnet. Thereafter, tetramethylbenzidine (TMB) was added to the mixture to perform chromogenic reaction and the production of the blue color considered as the presence of $B$. abortus in the solution. In a positive sample, a blue color was seen due to the peroxidase activity of HRP on its substrate $\mathrm{H}_{2} \mathrm{O}_{2}$ and subsequent oxidation of TMB chromogen. Whereas, the result was different in the negative sample since no HRP (HRP-SNP-IgG2) molecule was present in the solution after applying magnet in the previous step (Taheri et al., 2020). Schematic detection of B. abortus is given in figure 2 .

\subsection{Fluorescence assay using the immune magnetic beads and quantum dots for detection of Brucella}

Quantum dots (QDs) are nanocrystals made by semiconductor materials that present attractive photophysical properties (Salouti \& Ahangari, 2014). QDs are exceptionally bright, photostable and have high quantum yield. These properties make them suitable for sensing applications (Tallury, Malhotra, Byrne, \& Santra, 2010). Li et al. designed an immunosensor by using the immune magnetic beads (IMB) probe and quantum dots (QDs) - staphylococcal protein A (SPA) probe for the diagnosis of brucellosis. The IMB probe and serum were first mixed to let the antibodies against Brucellainteract with a multi-epitope fusion protein of Brucella outer membrane protein (rOMP) coated on the surface of the IMB probe. Thereafter, the fluorescence intensity from QDs which was enhanced significantly and correlated with the number of anti-Brucella antibodies was measured to determine the result. The steps of the experiment are shown in figure 3 (L. Li et al., 2017).

\section{Electrochemical Biosensors for characteization ofBrucella spp}

Other potential tools to identify pathogenic bacteria are electrochemical detection methods (Velusamy, Arshak, Korostynska, Oliwa, \& Adley, 2010). In this case, the bio-interaction process over the transducer generates the electrochemical signals, which is measured by the detector and analyzed with data analyzer (Gattani, Singh, Agrawal, Khan, \& Singh, 2019). Electrochemical biosensors can be classified into amperometric, potentiometric, impedimetric, voltammetric, and conductometric ones (Velusamy et al., 2010).

Electrochemical biosensors are classified into two label-dependent and label-free types based on the detection strategy. Label dependent electrochemical biosensors use the biological molecules such as enzymes, antibod- 
ies, metal nanoparticles, conductive polymers, etc. to induce a measurable electrical impulse. While the label free sensors are those that work on the basis of immobilization of the target analyte using a bio-receptor electrode and estimation in the changes of capacitance and resistance over the electrode surface (Gattani et al., 2019). A comparison of limit of detection (LOD) for the traditional methods with some biosenosrs is presented in Table 1. Electrochemical and optical methods are the most broadly utilized strategies in the development of Brucella biosensors. Consequently, biosensors can be considered as simple and inexpensive diagnostic tools with a comparable or even better detection limits compared to the traditional methods (Abbaspour, Norouz-Sarvestani, Noori, \& Soltani, 2015; Sattarahmady et al., 2015).

\subsection{Quartz crystal microbalance (QCM) aptasensor for detection of Brucella melitensis}

QCM sensors are composed of a thin piezoelectric plate with two metal electrodes on either side (Singh et al., 2013). These sensors are coated with immobilized bioreceptors such as aptamer (short synthetic oligonucleotide sequences of single stranded DNA or RNA with unique 3D structures; aptamer-based biosensors are called aptasensors) or antibody molecules for the target bacterium on their surface. Hence, QCM is a sensitive method which is performed based on the measurement of mass changes on quartz crystal surface (Bayramoglu, Ozalp, Oztekin, \& Arica, 2019; Urmann, Modrejewski, Scheper, \& Walter, 2016).

As shown in figure 4, Bayramoglu et al. designed a novel quartz crystal microbalance (QCM) aptasensor for the detection of Brucella melitensis (Bayramoglu et al., 2019). In this method, the surface of the magnetic nanoparticles was modified by 3-aminopropyltriethoxysilane (APTES) and then grafted with a hydrophilic macromonomer poly(ethyleneglycol)-methacrylate (PEG-MA) and glycidylmethacrylate (GMA). The specific aptamer sequence was also immobilized on the QCM chip and utilized for the identification of B. melitensis (Bayramoglu et al., 2019).

\subsection{Label-free impedance immunosensor using gold nanoparticles for characterization of Bru- cella melitensis}

The impedance method is one more quick and cheap substition for those methods using label-free biosensors (Wu et al., 2013). Most of these sensors are label-dependent that require labeling of bio-molecules to convert the antibody/antigen interaction into detectable electrochemical signals. In contrast, label-free impedance immunosensors show outstanding advantages such as speed, cheapness and ease of operation (Varshney, Li, Srinivasan, \& Tung, 2007).

$\mathrm{Wu}$ et al. designed a label-free impedance immunosensor based on the gold nanoparticles with modified screen-printed carbon electrodes (GNP-SPCEs) for rapid detection of Brucella melitensis. Cyclic voltammetry $(\mathrm{CV})$ and electrochemical impedance spectroscopy (EIS) were utilized to characterize interaction of the Brucella melitensis antigens on the surface of GNP-SPCEs against antibody molecules. This designed biosensor was able to detect $1 \times 10^{4}$ and $4 \times 10^{5} \mathrm{CFU} / \mathrm{mL}$ of Brucella melitensis in pure culture and milk samples in less than $1.5 \mathrm{~h}$, respectively (Wu et al., 2013).

\subsection{Zinc oxide nanoparticles (ZnO-NPs) sensors for diagnosis ofBrucella}

$\mathrm{ZnO}$ NPs are new type of cheap and low-toxicity nanomaterials which have several therapeutic applications against cancers, microbial infections, inflammations, diabetes, as well as usage in bioimaging and drug delivery (Wahab, Khan, Ahmad, Musarrat, \& Al-Khedhairy, 2017). Wahab et al. developed a ZnO-NPs based sensor for the identification of Brucella. They tried to design an affordable and low-cost biosensor to detect Brucella in milk samples to be used by rural people. To do this, the anti-Brucellaantibody was functionalized on $\mathrm{ZnO}-\mathrm{NPs}$ and the resulted NPs were deposited on aluminum sheets (Al-sheet). The developed Al-sheets were then used as electrode components for voltametric detection (CV) of the bacterium (Wahab et al., 2017). The detection scheme is shown in figure 5 .

\section{Conclusion}

Conventional methods for diagnosis of Brucella infections may need expensive laboratory equipment, long time to achieve the final results and skilled personnel to interpret them. Therefore, efforts are being made to 
develop new diagnostic methods with improved characteristics. Utilization of biosensors can be considered as one of those promising approaches in this case. Among different types of biosensors, optical biosensors, seem to be appropriate choices for detection of Brucellaregarding their advantages including high sensitivity and specificity, shorter detection time, and ease of application without the need for dedicated equipment. When conjugated with nanoparticles, these benefits are extended particularly in colormetric methods. In this regard, gold nanoparticles are mainly employed in colorimetric immunoassays but their high cost and short lifetime prevent them from being utilized in laboratories. However, magnetic and silica nanoparticles have advantages like simple synthesis and cheap production and they can be employed in optical biosensors to introduce efficient methods for rapid, simple, and easy detection of Brucella in different types of samples. Such quick and proper optical methods can also be applied to identify other infectious bacteria.

\section{Aknowledgement}

The authors are grateful to Bu-Ali Sina University of Hamedan.

\section{References}

Abbaspour, A., Norouz-Sarvestani, F., Noori, A., \& Soltani, N. (2015). Aptamer-conjugated silver nanoparticles for electrochemical dual-aptamer-based sandwich detection of Staphylococcus aureus.Biosensors and Bioelectronics, 68 , 149-155. https://doi.org/10.1016/j.bios.2014.12.040

Ahangari, A., Salouti, M., \& Saghatchi, F. (2016). Gentamicin-gold nanoparticles conjugate: a contrast agent for X-ray imaging of infectious foci due to Staphylococcus aureus. IET nanobiotechnology, 10 (4), 190-194. https://doi.org/10.1049/iet-nbt.2015.0034

Alves, C. J., Figueiredo, S. M. d., Azevedo, S. S. d., Clementino, I. J., Keid, L. B., Vasconcellos, S. A., Batista, C. D. S. A., Rocha, V. C. M. \& Higino, S. S. (2010). Detection of Brucella ovis in ovine from Paraíba State, in the Northeast region of Brazil. Brazilian Journal of Microbiology, 41 (2), 365-367. https://doi.org/10.1590/S1517-83822010000200016

Amini, B., Kamali, M., Salouti, M., \& Yaghmaei, P. (2018). Spectrophotometric, colorimetric and visually detection of Pseudomonas aeruginosa ETA gene based gold nanoparticles DNA probe and endonuclease enzyme. Spectrochimica Acta Part A: Molecular and Biomolecular Spectroscopy, 199 , 421-429. https://doi.org/10.1016/j.saa.2018.03.056

Bayramoglu, G., Ozalp, V. C., Oztekin, M., \& Arica, M. Y. (2019). Rapid and label-free detection of Brucella melitensis in milk and milk products using an aptasensor. Talanta, 200 , 263-271. https://doi.org/10.1016/j.talanta.2019.03.048

Eltzov, E., \& Marks, R. S. (2016). Miniaturized flow stacked immunoassay for detecting Escherichia coli in a single step.Analytical chemistry, 88 (12), 6441-6449.https://doi.org/10.1021/acs.analchem.6b01034

Emameian, A., Ahangari, A., Salouti, M., \& Amirmozafari, N. (2020). Enhanced effect of Amikacin in conjugation with gold nanopartcles as a carrier to kill Pseudomonas aeruginosa. Nanochemistry Research, 5 (2), 179-184.https://doi.org/10.22036/NCR.2020.02.008

Gattani, A., Singh, S. V., Agrawal, A., Khan, M. H., \& Singh, P. (2019). Recent progress in electrochemical biosensors as point of care diagnostics in livestock health. Analytical biochemistry, 579 , 25-34. https://doi.org/10.1016/j.ab.2019.05.014

Le, T. N., Tran, T. D., \& Kim, M. I. (2020). A Convenient Colorimetric Bacteria Detection Method Utilizing Chitosan-Coated Magnetic Nanoparticles. Nanomaterials, 10 (1), 92.https://doi.org/10.3390/nano10010092

Li, L., Yin, D., Xu, K., Liu, Y., Song, D., Wang, J., Zhao, C., Song, X. \& Li, J. (2017). A sandwich immunoassay for brucellosis diagnosis based on immune magnetic beads and quantum dots. Journal of pharmaceutical and biomedical analysis, 141 , 79-86. https://doi.org/10.1016/j.jpba.2017.03.002 
Li, S., Liu, Y., Wang, Y., Wang, M., Liu, C., \& Wang, Y. (2019). Rapid detection of Brucella spp. and elimination of carryover using multiple cross displacement amplification coupled with nanoparticles-based lateral flow biosensor. Frontiers in cellular and infection microbiology, 9 , 78. https://doi.org/10.3389/fcimb.2019.00078

Mehrotra, P. (2016). Biosensors and their applications-A review.Journal of oral biology and craniofacial research, 6 (2), 153-159. https://doi.org/10.1016/j.jobcr.2015.12.002

Narmani, A., Kamali, M., Amini, B., Kooshki, H., Amini, A., \& Hasani, L. (2018). Highly sensitive and accurate detection of Vibrio cholera O1 OmpW gene by fluorescence DNA biosensor based on gold and magnetic nanoparticles. Process Biochemistry, 65 , 46-54. https://doi.org/10.1016/j.procbio.2017.10.009

Pal, D., Boby, N., Kumar, S., Kaur, G., Ali, S. A., Reboud, J., Shrivastava, S., Gupta, P. K., Cooper, J. M. \& Chaudhuri, P. (2017). Visual detection of Brucella in bovine biological samples using DNA-activated gold nanoparticles. Plos one, 12 (7), e0180919. https://doi.org/10.1371/journal.pone.0180919

Pereira, C. R., Cotrim de Almeida, J. V. F., Cardoso de Oliveira, I. R., Faria de Oliveira, L., Pereira, L. J., Zangerônimo, M. G., Large, A. P\& Dorneles, E. M. S. (2020). Occupational exposure to Brucellaspp.: A systematic review and meta-analysis. PLoS neglected tropical diseases, 14 (5), e0008164. https://doi.org/10.1371/journal.pntd.0008164

Rubab, M., Shahbaz, H. M., Olaimat, A. N., \& Oh, D.-H. (2018). Biosensors for rapid and sensitive detection of Staphylococcus aureus in food. Biosensors and Bioelectronics, 105 , 49-57. https://doi.org/10.1016/j.bios.2018.01.023

Salouti, M., \& Ahangari, A. (2014). Nanoparticle based drug delivery systems for treatment of infectious diseases (Vol. 552): InTech. http:// doi.org/10.5772/58423

Sattarahmady, N., Kayani, Z., \& Heli, H. (2015). Highly simple and visual colorimetric detection of Brucella melitensis genomic DNA in clinical samples based on gold nanoparticles. Journal of the Iranian Chemical Society, 12 (9), 1569-1576. https://doi.org/10.1007/s13738-015-0629-5

Shahbazi, R., Salouti, M., Amini, B., Jalilvand, A., Naderlou, E., Amini, A., \& Shams, A. (2018). Highly selective and sensitive detection of Staphylococcus aureus with gold nanoparticle-based core-shell nano biosensor. Molecular and cellular probes, 41 , 8-13. https://doi.org/10.1016/j.mcp.2018.07.004

Shams, A., Rahimian Zarif, B., Salouti, M., Shapouri, R., \& Mirzaii, S. (2019). Designing an immunosensor for detection of Brucella abortus based on coloured silica nanoparticles. Artificial Cells, Nanomedicine, and Biotechnology, 47 (1), 2562-2568. https://doi.org/10.1080/21691401.2019.1626403

Singh, A., Poshtiban, S., \& Evoy, S. (2013). Recent advances in bacteriophage based biosensors for food-borne pathogen detection.Sensors, 13 (2), 1763-1786. https://doi.org/10.3390/s130201763

Sun, Q., Zhao, G., \& Dou, W. (2016). An optical and rapid sandwich immunoassay method for detection of Salmonella pullorum and Salmonella gallinarum based on immune blue silica nanoparticles and magnetic nanoparticles. Sensors and Actuators B: Chemical, 226 , 69-75. https://doi.org/10.1016/j.snb.2015.11.117

Taheri, H., Amini, B., Kamali, M., Asadi, M., \& Naderlou, E. (2020). Functionalization of antiBrucella antibody based on SNP and MNP nanoparticles for visual and spectrophotometric detection ofBrucella. Spectrochimica Acta Part A: Molecular and Biomolecular Spectroscopy, 229 , 117891. https://doi.org/10.1016/j.saa.2019.117891

Tallury, P., Malhotra, A., Byrne, L. M., \& Santra, S. (2010). Nanobioimaging and sensing of infectious diseases. Advanced drug delivery reviews, 62 (4-5), 424-437. https://doi.org/10.1016/j.addr.2009.11.014

Urmann, K., Modrejewski, J., Scheper, T., \& Walter, J.-G. (2016). Aptamer-modified nanomaterials: principles and applications.BioNanoMaterials, 18 (1-2). https://doi.org/10.1515/bnm-2016-0012

Varshney, M., Li, Y., Srinivasan, B., \& Tung, S. (2007). A label-free, microfluidics and interdigitated array microelectrode-based impedance biosensor in combination with nanoparticles immunoseparation for 
detection of Escherichia coli O157: H7 in food samples.Sensors and Actuators B: Chemical, 128 (1), 99107.https://doi.org/10.1016/j.snb.2007.03.045

Table 1. Limit of detection of several methods for investigation of Brucella .

\begin{tabular}{|c|c|c|c|}
\hline Method & Recognition element & Analyte & LOD (References) \\
\hline Electrochemical & Aptamer & B. melitensis & $\begin{array}{l}10^{2}-10^{7} \mathrm{CFU} / \mathrm{ml} \\
\text { (Bayramoglu et al., 2019) }\end{array}$ \\
\hline Electrochemical & Antibody & B. melitensis & $\begin{array}{l}1 \times 10^{4} \mathrm{CFU} / \mathrm{ml} \text { (Amini } \\
\text { et al., 2018) }\end{array}$ \\
\hline Optical (colorimetric) & DNA & B. abortus & $\begin{array}{l}10^{3} \mathrm{CFU} / \mathrm{ml} \text { (Pal et al., } \\
2017)\end{array}$ \\
\hline Optical (colorimetric) & DNA & Brucella spp & $\begin{array}{l}1.09 \mathrm{pg} / \mathrm{ml}(\text { Eltzov \& } \\
\text { Marks, 2016) }\end{array}$ \\
\hline Optical (colorimetric) & DNA & B. melitensis & $\begin{array}{l}3.32 \mathrm{pg} / \mathrm{ml} \\
\text { (Sattarahmady et al., } \\
2015 \text { ) }\end{array}$ \\
\hline Optical (colorimetric) & Antibody & B. abortus & $\begin{array}{l}450 \mathrm{CFU} / \mathrm{ml} \text { (Sun et al., } \\
2016)\end{array}$ \\
\hline PCR assay & - & B. melitensis & $\begin{array}{l}20 \text { pg (Sattarahmady et } \\
\text { al., 2015) }\end{array}$ \\
\hline Protein array & - & B. melitensis & $\begin{array}{l}1 \times 10^{6} \mathrm{CFU} / \mathrm{ml} \\
\text { (Sattarahmady et al., } \\
2015)\end{array}$ \\
\hline $\begin{array}{l}\text { Fluoro-immunosensing } \\
\text { system }\end{array}$ & - & B. melitensis & $\begin{array}{l}2.7 \mu \mathrm{g} / \mathrm{L} \text { (Sattarahmady } \\
\text { et al., 2015) }\end{array}$ \\
\hline
\end{tabular}

Figure 1. Visual detection of Brucella cells using nanobiosensor based oligo-AuNPs probes (Pal et al., 2017).

Figure. 2. Schematic detection of Brucella using MNPs-SNPs. (A) in the presence of the target bacterial cells, (B) in the absence of the target bacterial cells.

Figure 3. The sandwich immunoassay for diagnosis of Brucellainfection based on the IMB and QDs - SPA probes (L. Li et al., 2017).

Figure 4. Steps for the detection of B. melitensis using QCM aptasensor (Bayramoglu et al., 2019).

Figure 5. Characterization of Brucella abortus cells using antibody-ZnO-NPs (Wahab et al., 2017).

\section{Hosted file}

image1.emf available at https://authorea.com/users/411892/articles/520771-biosensors-

functionalized-with-nanoparticles-for-rapid-detection-of-brucella

Figure 1. 
(A)
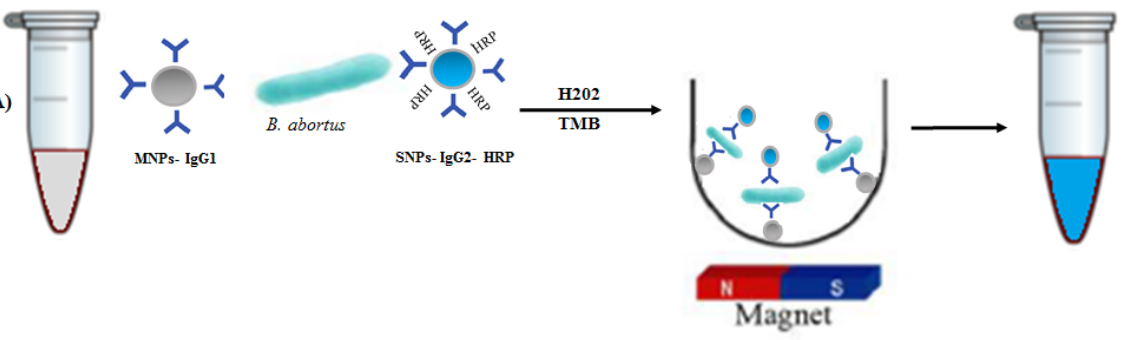

(B
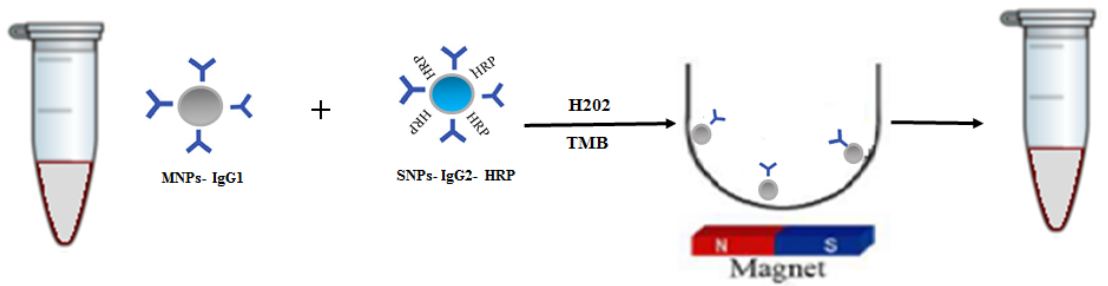

Figure 2 .

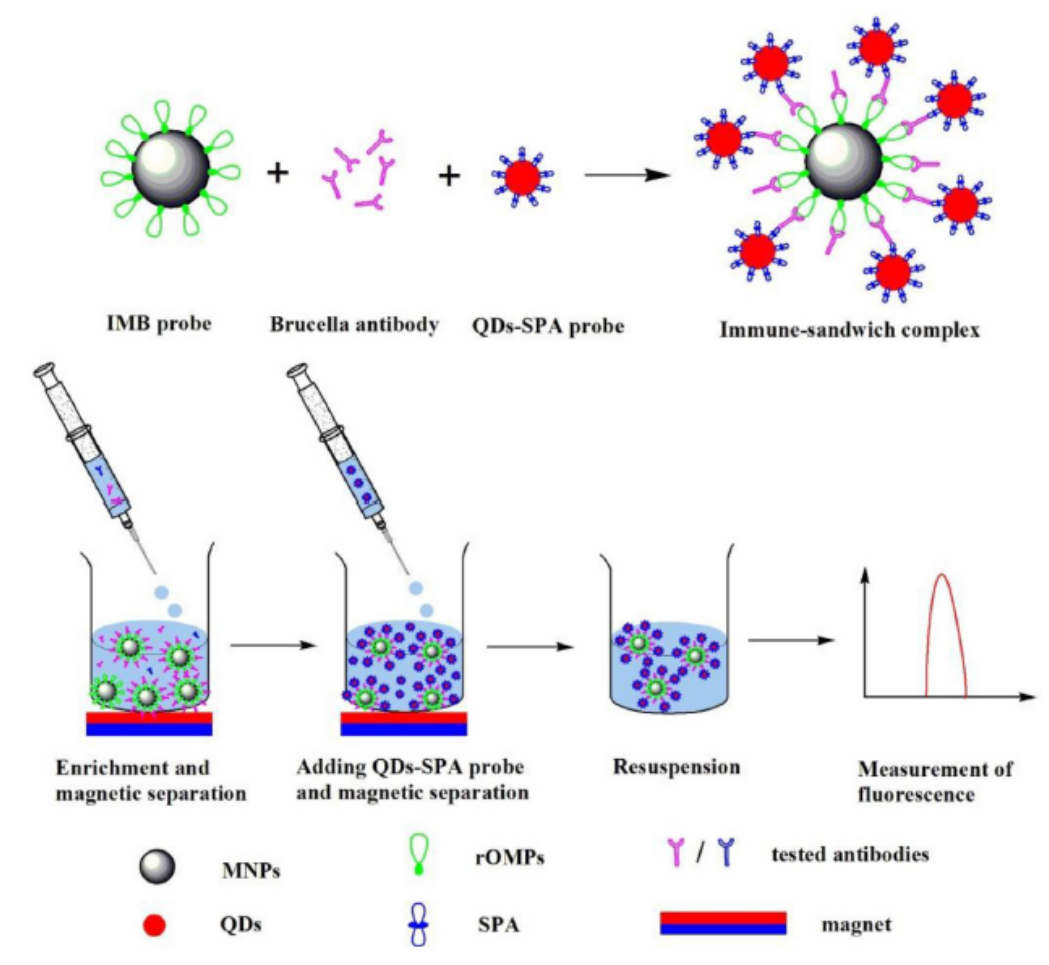

Figure 3.

\section{Hosted file}

image4.emf available at https://authorea.com/users/411892/articles/520771-biosensorsfunctionalized-with-nanoparticles-for-rapid-detection-of-brucella

Figure 4.

Hosted file 
image5.emf available at https://authorea.com/users/411892/articles/520771-biosensorsfunctionalized-with-nanoparticles-for-rapid-detection-of-brucella

Figure 5 .

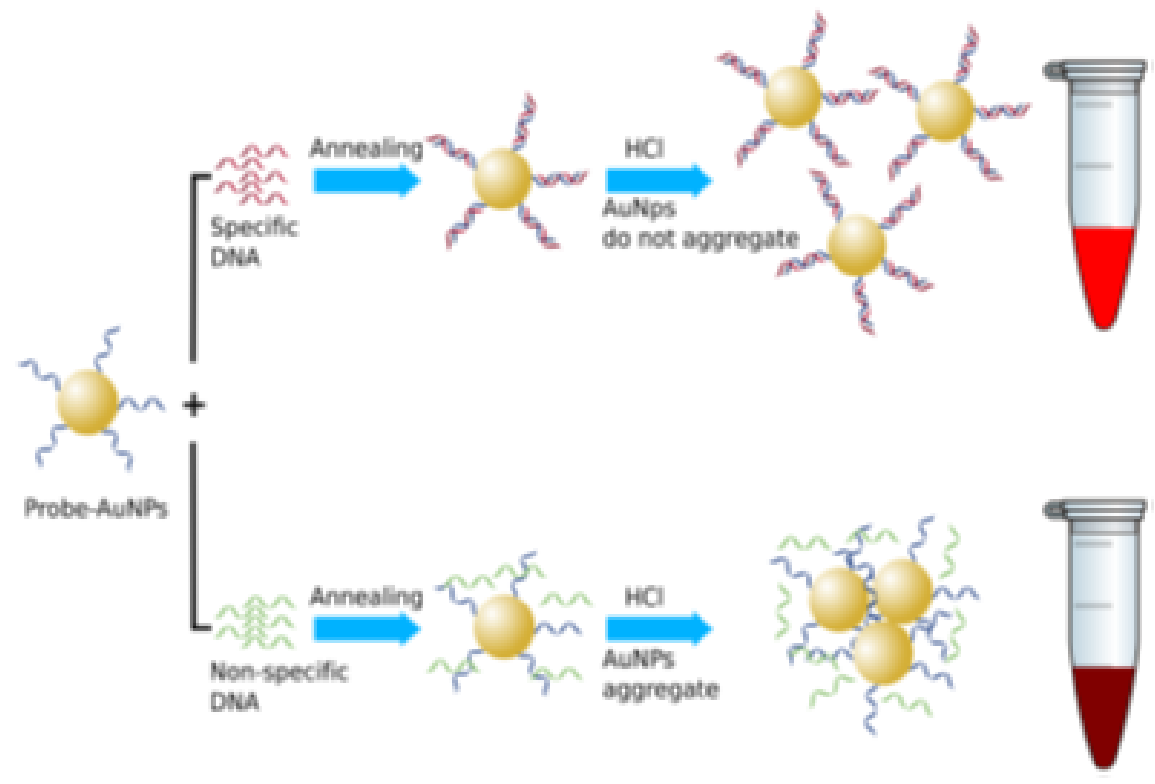

(A)

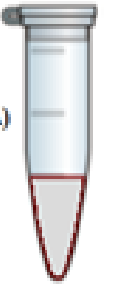

$(B$

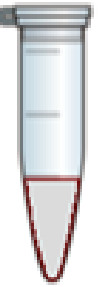

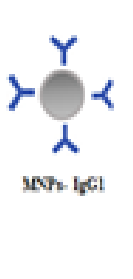

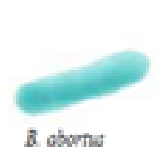

$r^{*} \alpha$ $\sin$ lact $\operatorname{axp}$

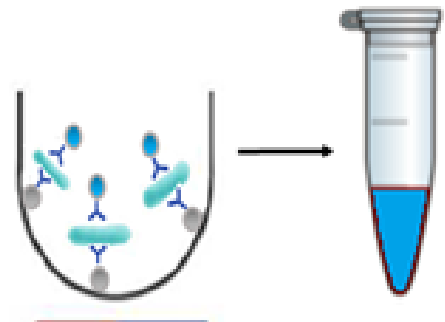

Magnet
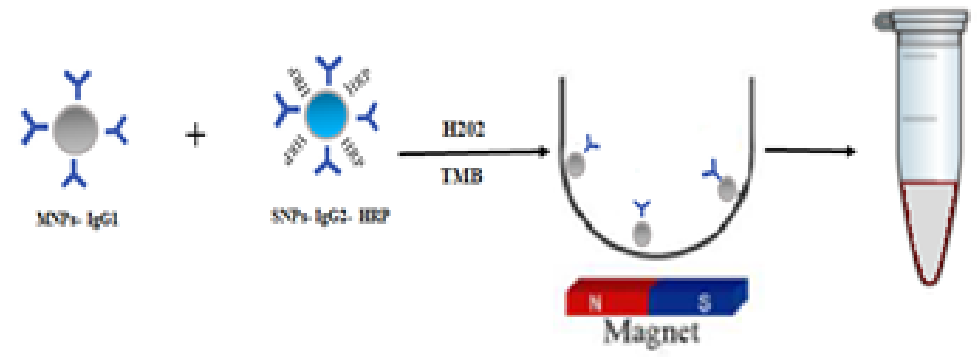

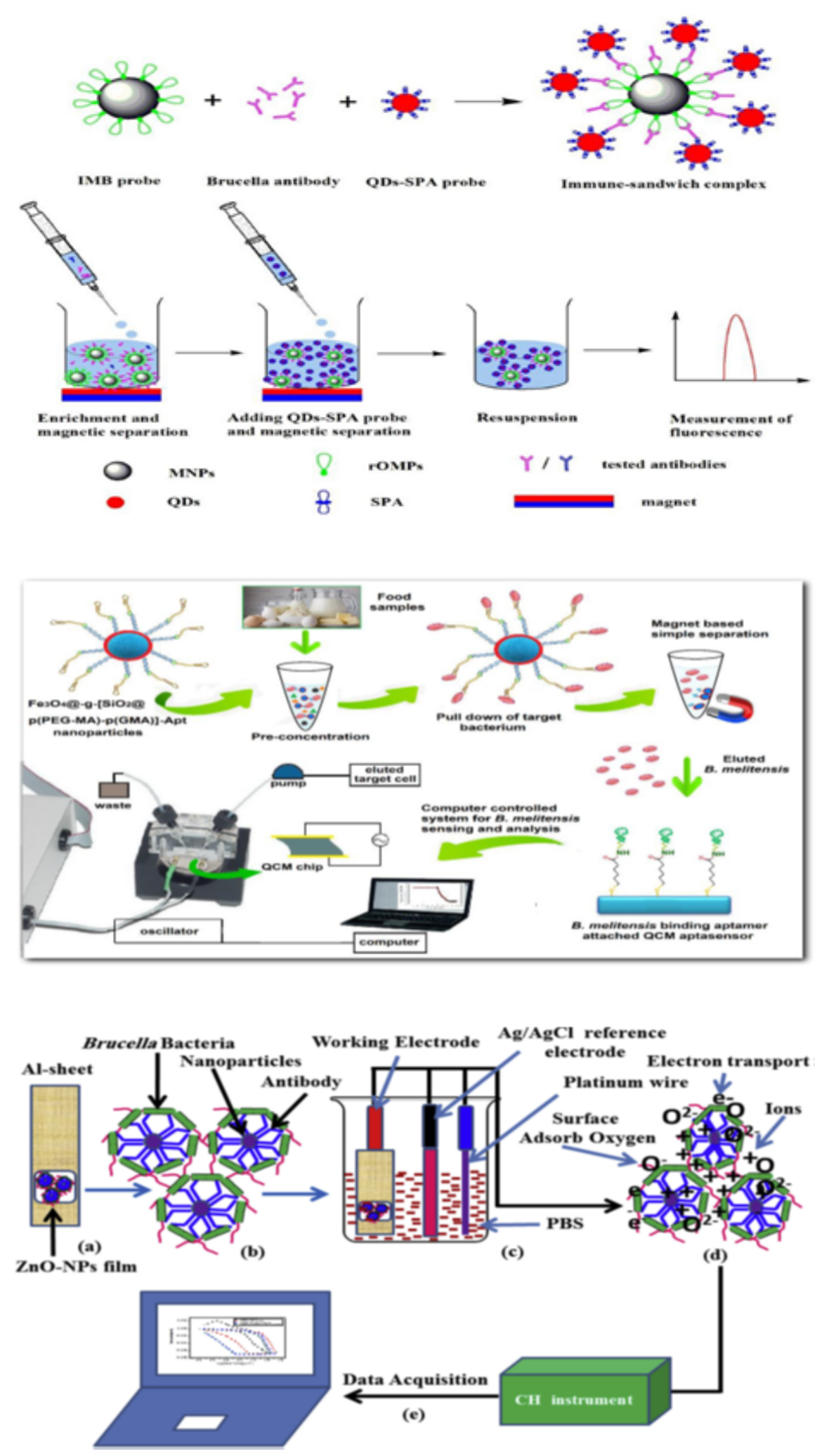

Hosted file 
Table 1.pdf available at https://authorea.com/users/411892/articles/520771-biosensorsfunctionalized-with-nanoparticles-for-rapid-detection-of-brucella 